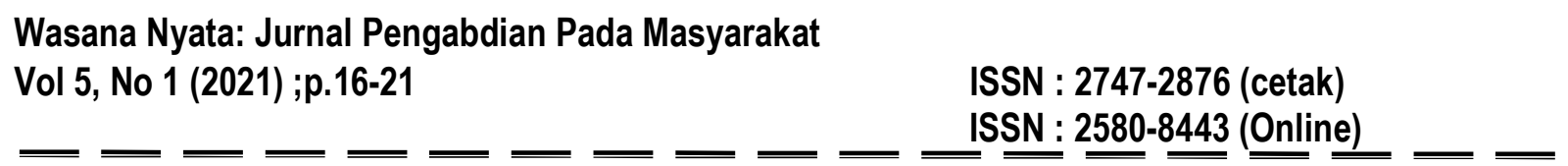

\title{
Upaya Memultiliterasikan Warga \\ Di Desa Teloyo, Kecamatan Wonosari, Kabupaten Klaten
}

\author{
Ipung Sri Purwanti Hery ${ }^{1}$, Endah Nawangsasi ${ }^{2}$, Hanif Safika Rizky ${ }^{3}$ \\ STIE AUB Surakarta
}

\begin{abstract}
ABSTRAK
Multiliterasi adalah salah satu upaya untuk membangun masyarakat berpengetahuan yang pada akhirnya dapat mencerdaskan kehidupan bangsa (Alhumami, 2018). Kecerdasan kehidupan bangsa bersumber pada kecerdasan warga di setiap desa. Kecerdasan bukan hanya berbentuk kemampuan membaca dan menulis namun juga kemampuan akan berbagai hal yang terkait dengan kemajuan teknologi dan informasi. Kemudahan akses informasi dan teknologi ini bisa membantu warga desa menjadi berpengetahuan di berbagai hal atau disebut multiliterasi. Dari hasil kegiatan Pengabdian Kepada Masyarakat yang berupa Penyuluhan tentang Upaya Memultiliterasikan Warga di Desa Teloyo, Kecamatan wonosari Kabupaten Klaten kami menemukan hasil bahwa (1) Warga perlu mengetahui ihwal pendidikan di lingkungannya, misalnya jenjang pendidikan warga dan berbagai hal terkait pembangunan Sumber Daya Manusia. (2) Mayoritas penduduk berusia antara 12 - 60 tahun dan sebagian besar diantara mereka adalah pelajar (SD, SLTP dan SLTA) yang sangat rentan terhadap kemampuan membaca, serta minim terhadap akses multiliterasi. (3) Pemangku kepentingan dari pihak kepala daerah (bupati/kepala desa) belum maksimal dalam mendukung warganya menjadi multiliterat. Tujuan dari kegiatan Pengabdian Kepada Masyarakat, sebagai realisasi salah satu dari Tri Dharma Perguruan Tinggiini adalah (1) Membantu warga untuk melek dalam berbagai hal, minimal mencakup literasi: baca-tulis, sains, numerasi, media, finansial, budaya dan kewargaan. (2) Membantu warga memahami literasi kriminal, kesehatan, dan keselamatan dengan cara mengarahkankompetensiuntuk memecahkan masalah kompleks, meliputi kemampuan berpikir kritis/memecahkan masalah, kreativitas, komunikasi, dan kolaborasi (3) Memahamkan bahwa multiliterat, kompetensi, dan karakter sebagai paradigma pembangunan Indonesia selayaknya diimplementasikan pada konteks keluarga, sekolah, dan masyarakat.
\end{abstract}

Kata Kunci: Multiliterasi, Komunikasi, Implementasi, Realisasi, Pembangunan Desa

\section{PENDAHULUAN}

Demografi Desa. Teloyo, berdasarkan demografi tahun 2020, dengan Luas $\pm 182,2250$ Ha, dan jumlah penduduk 4.964 jiwa adalah terletak pada 6 51'46" sampai dengan $711^{\prime}$ '47" LS dan 109 40'19" sampai dengan 110 03'06" BT. Desa ini berbatasan dengan empat desa tetangga sebagai berikut : Sebelah Utara Desa Krajan Kecamatan Gatak. Kabupaten Sukoharjo, Sebelah Timur Desa Jetis Kecamatan Baki, kabupaten Sukoharjo, Sebelah Selatan Desa Kingkang Kecamatan Wonosari dan Sebelah Barat Desa Pandanan Kecamatan Wonosari, Kabupaten Klaten.

Sesuai dengan kondisi geografis, dimana tanah persawaahan adalah wilayah terbesar, maka sebagian besar penduduk bekerja sebagai petani dan buruh tani/ buruh lepas yaitu 2199 jiwa. Sedangkan mayoritas penduduk berusia antara 12 - 60 tahun dan sebagian besar diantara mereka adalah pelajar (SD, SLTP dan SLTA) yang sangat rentan terhadap kemampuan membaca, serta minim terhadap akses multiliterasi. Untuk itulah maka dalam program pengabdian kepada masyarakat STIE AUB Surakarta, kami menuju Desa Teloyo, Kecamatan Wonosari Kabupaten Klaten sebagai tempat berdiskusi untuk UPAYA MEMULTILITERASIKAN WARGA, yang telah dilaksanakan pada hari Ahad 20 Desember, 2020. Harapan kami kegiatan ini dapat 
memberikan wawasan dan menambah literasi bagi warga desa umumnya dan Tim Pengabdian Masyarakat STIE “AUB” khususnya.

\section{HASIL PENGABDIAN DAN PEMBAHASAN}

\section{Asesmen Kompetensi Siswa dan Masyarakat Desa Teloyo.}

Upaya Memultiliterasikan Warga Desa Teloyo, Kecamatan Wonosari, Kabupaten Klaten ini bersifat penyuluhan yang telah dilaksanakan pada Hari Ahad, 20 Desember 2020 dari pukul 10.00 hingga pukul 14.00 dihadiri oleh Kepala Desa dan Perangkat Desa serta 25 Warga berjalan dengan tertib dan lancar. Dalam kegiatan tersebut para warga sangat antusias dalam mengikuti penyuluhan, namun karena di Desa Teloyo belum disediakan Perpustakaan Desa secara khusus, maka kegiatan pembinaan yang bersifat literasi dasar (membaca, menulis dan berhitung) jarang dilakukan. Hanya dalam kesempatan tertentu ketika warga datang di Kantor Kalurahan (tempat Perpustakaan Sementara) petugas memberikan penyuluhan. Disamping itu sebagian besar warga desa telah bebas dari buta aksara. Bahkan mayoritas anak muda yang hadir dalam penyuluhan dan diskusi tentang multiliterasi telah mengenal dan mengaplikasikan teknologi informasi secara digital. Kemampuan para peserta dalam mengenal dan mengaplikasikan teknologi informasi secara digital inilah yang membuat mereka aktif dan antusias untuk mengetahui lebih dalam tentang multiliterasi warga. Sebagai generasi penerus, para kawula muda ini berniat untuk menjadi media dalam membangun desa dan mencerdaskan warganya. Yang menjadi kendala adalah kurangnya pengarahan dari Kepala Desa dalam hal peningkatan pengetahuan dan ketrampilan yang menjadi unsur utama multiliterasi warga.Videotron (atau spanduk) sebagai media yang dapat dimanfaatkan untuk menyampaikan materi secara visual-dinamik di area public belum tersedia. Penyuluhan tentang multiliterasi sangat bermanfaat bagi warga. Oleh karena itu para peserta mengharapkan penyuluhan lebih lanjut sampai terbentuknya fasilitas publik seperti Perpustakaan Desa serta media publik lainnya, sebagai modal dasar untuk meningkatkan pengetahuan warga.

Beberapa studi menunjukkan kemampuan membaca siswa Indonesia hingga orang dewasa berada pada level rendah Demikian halnya dengan kompetensi siswa dan masyarakat desa Teloyo pada umumnya. Progress in International Reading Literacy Study (PIRLS, 2011) menempatkan Indonesia pada level ke-42 dari 45 negara,

Asesmen Kompetensi Siswa Indonesia bagi siswa SD kelas IV yang diadakan Puspendik Kemdikbud (2016) menunjukkan kemampuan membaca domain nonsastra 43,34\%, sedangkan domain sastra 27,65\%. Programme for International Student Assessment (PISA) bagi siswa usia 15 tahun (kelas IX/X) menempatkan Indonesia pada level ke-57 (65 negara peserta, tahun 2009), level ke-64 (65 negara peserta, tahun 2012), dan tetap pada level ke-64 (72 peserta tahun 2015). Sementara itu, kemampuan membaca orang dewasa berdasarkan hasil The Programme for the International Assessment of Adult Competencies (PIACC, Maret 2016) juga dalam posisi rendah, level terbawah dari negara peserta. Data sejak SD hingga orang dewasa tampak ajek.Berikutnya, Menkeu Sri Mulyani Indrawati, di penghujungm Pertemuan Tahunan Dana Moneter International (IMF) dan Bank Dunia 2017, di Washington DC, US (14 Oktober 2017) mengatakan kualitas pendidikan di Indonesia sangat tertinggal jika dibandingkan dengan negara-negara maju khususnya negara-negara dalam kawasan Organisation for Economic Co-operation and Development (OECD).

Indonesia memerlukan 45 tahun agar mencapai tingkat kemampuan membaca setara mereka, sedangkan untuk sains diperlukan 75 tahun.Benarkah demikian?Rentang waktu 45 tahun 
dan 75 tahun itu tidak akan terjadi jika upaya gerakan literasi yang dilakukan Kemendikbud sejak akhir 2015 melalui Gerakan Literasi Sekolah dan Gerakan Literasi Nasional (Oktober 2017) didukung oleh seluruh masyarakat dalam berbagai peran. Sistem sudah dibangun oleh beberapa pemangku kepentingan, juga dukungan Presiden Jokowi tentang bebas ongkos kirim buku tiap bulan pada tanggal 17 oleh PT Pos Indonesia.Namun, pemangku kepentingan dari pihak kepala daerah (gubernur/bupati/walikota) belum maksimal dalam mendukung warganya menjadi multiliterat.

Didukung program USAID Prioritas, dari 93 pemerintah daerah (pemda), 18 kabupaten dan satu kota Mitra Program USAID dinyatakan berpredikat amat baik/baik dan mendapatkan penghargaan Literasi Prioritas dari Mendikbud pada 20 Maret 2017. Beberapa kapemda juga membangun warganya agar menjadi literat. Namun, para kapemda ini tidak akan dapat membangun daerahnya secara maksimal jika hanya dengan mengandalkan stafnya. Masyarakat harus dilibatkan dan membuat mereka menjadi multiliterate merupakan modalnya.

\section{Multiliterasi}

Multiliterat berarti 'melek dalam berbagai hal', minimal mencakup literasi: baca-tulis, sains, numerasi, media, finansial, budaya dan kewargaan. Selain literasi dasar (World Economy Forum: 2015) ini, perlu ditambahkan literasi kriminal, kesehatan, dan keselamatan (jalan, bencana). Selain itu, perlu diimbangi dengankompetensiuntuk memecahkan masalah kompleks, meliputi kemampuan berpikir kritis/memecahkan masalah, kreativitas, komunikasi, dan kolaborasi. Selanjutnya, penguatan pendidikan karakter beradaptasi pada lingkungan yang dinamis juga perlu dilakukan dengan memfokuskan pada lima karakter utama, yaitu religius, nasionalis, mandiri, gotong royong, dan integritas (Perpres Nomor 87 Th 2017). Multiliterat, kompetensi, dan karakter sebagai paradigma pembangunan Indonesia diimplementasikan pada konteks keluarga, sekolah, dan masyarakat. Warga setiap PEMDA semestinya mempunyai kemampuan multiliterat yang dicapai secara bertahap. Indikator pencapaiannya dapat dikaitkan dengan Undang-Undang Republik Indonesia Nomor 23 Tahun 2014 tentang Pemerintahan Daerah, Pasal 12, yang disesuaikan dengan konteks pemda terkait. Apa yang terjadi pada kondisi kemampuan multiliterat warga yang tidak/kurang terbina? Setiap warga tidak cukup peka terhadap kondisi daerahnya, dan kurang mempunyai keinginan berkontribusi membangun daerahnya akibat ketidaktahuannya. Jika demikian halnya, ada kecenderungan warga tidak akan dapat maju dalam sekian aspek kehidupan sesuai yang didambakan.

\section{Unsur Pokok Pengembangan Daerah}

Dalam Undang-Undang Republik Indonesia Nomor 23 Tahun 2014 tentang Pemerintahan Daerah, pada butir $b$, dinyatakan bahwa "penyelenggaraan pemerintahan daerah diarahkan untuk mempercepat terwujudnya kesejahteraan masyarakat melalui peningkatan pelayanan, pemberdayaan, dan peran serta masyarakat, serta peningkatan daya saing daerah dengan memperhatikan prinsip demokrasi, pemerataan, keadilan, dan kekhasan suatu daerah dalam sistem Negara Kesatuan Republik Indonesia”. Pada Bagian Ketiga Urusan Pemerintahan Konkuren Pasal 11, dinyatakan: (1) Urusan pemerintahan konkuren sebagaimana dimaksud dalam Pasal 9 ayat (3) yang menjadi kewenangan Daerah terdiri atas Urusan Pemerintahan Wajib dan Urusan Pemerintahan Pilihan. (2) Urusan Pemerintahan Wajib sebagaimana dimaksud pada ayat (1) terdiri atas Urusan Pemerintahan yang berkaitan dengan Pelayanan Dasar dan Urusan Pemerintahan yang tidak berkaitan dengan Pelayanan Dasar.(3) Urusan Pemerintahan Wajib yang berkaitan dengan Pelayanan Dasar sebagaimana dimaksud pada ayat (2) adalah Urusan 
Pemerintahan Wajib yang sebagian substansinya merupakan Pelayanan Dasar. Selanjutnya, pada Pasal 12, dinyatakan ada tiga urusan pemerintahan yang bersifat wajib dan pilihan, yaitu:

(1) Urusan Pemerintahan Wajib yang berkaitan dengan Pelayanan Dasarsebagaimana dimaksud dalam Pasal 11 ayat (2) meliputi: (a)pendidikan; (b) kesehatan; (c) pekerjaan umum danpenataan ruang; (d) perumahan rakyat dan kawasanpermukiman; (e) ketenteraman, ketertiban umum, danpelindungan masyarakat; dan (f). sosial. Indikator ini dapat dikaitkan dengan indikator penguasaan literasi dasar.

(2) Urusan Pemerintahan Wajib yang tidak berkaitan dengan Pelayanan Dasar sebagaimana dimaksud dalam Pasal 11 ayat (2) meliputi:(a) tenaga kerja; (b) pemberdayaanperempuan dan pelindungan anak; (c) pangan; (d) pertanahan;(e) lingkungan hidup; (f) administrasikependudukan dan pencatatan sipil; (g) pemberdayaanmasyarakat dan desa; (h) pengendalian penduduk dankeluarga berencana; (i) perhubungan; (j) komunikasidan informatika (k) koperasi, usaha kecil, danmenengah; (l) penanaman modal; (m) kepemudaan danolahraga; (n) statistik; (o) persandian; (p) kebudayaan;(q) perpustakaan; dan(r) kearsipan.

(3) Urusan Pemerintahan Pilihan sebagaimana dimaksud dalam Pasal 11 ayat (1) meliputi: (a) kelautan danperikanan; (b) pariwisata; (c) pertani(d) kehutanan;(e) energi dan sumber daya mineral; (f) perdagangan; (g) perindustrian; dan (h) transmigrasi.Ketiga aspek ini dapat menjadi indikator pembangunansuatu daerahapakah ketercapaian sudah didapatkan atau belum sesuai dengan konteks daerah.

\section{Pemanfaatan Videotron Informatif}

Butir-butir dalam Pasal 12 pada umumnya dipahami masyarakat sebagai tanggung jawab kepala daerah dan jajarannya.Padahal, sesungguhnya ketika warga ikut terlibat aktif, kondisi dimungkinkan bisa interaktif karena warga mengetahui kondisi daerahnya dan dapat diminta aktif terlibat dalam membangun daerahnya sesuai kapasitas masing-masing.

Agar warga suatu daerah peduli, informasi tentang tiga urusan di atas perlu disampaikan ke masyarakat.Media yang dapat digunakan adalah videotron (atau spanduk; jika pemdabelum dapat menyediakan fasilitas videotron) karena media ini dapat menyampaikan materi secara visual-dinamik di area public dengan memperhatikan penempatannya yaitu harus pada area strategis dan tidak menyebabkan distraktor, misalnya pada pinggir jalan/area keramaian yang memicu kecelakaan. Area pusat perbelanjaan dan area layanan publik, seperti halaman rumah sakit, halaman kantor perbankan, halaman bandara, halaman perkantoran pemda, dll. dapat menjadi alternatif penempatan videotron ini. Warga dapat melihat informasi nirsuara ini (hanya mengandalkan aspek visual) karena suara dapat menjadi distractor. Informasi berbagai urusan pemda disajikan secara komunikatif dan menarik dalam bentuk infografis yang mudah dipahami awam (literasi media/visual).

\section{Kesimpulan}

Warga perlu mengetahui ihwal pendidikan di lingkungannya, misalnya jenjang pendidikan warga dan berbagai hal terkait pembangunan Sumber Daya Manusia. Aspek kesehatan: penyakit yang rawan diderita masyarakat dan berpotensi menjadi bencana nasional (seperti kasus pandemic Covid-19) saat ini. Mengenali gejala, proses penularan, penanggulangan, pencegahan, dengan melakukan 3M yakni Memakai masker, Mencuci tangan dengan sabun dan Menjaga jarak dengan menghindari kerumunan, dsb. Pada pokoknya, berbagai aspek yang terkait 
dengan kehidupan warga dan keberlangsungan Pemerintah Daerah (PEMDA) di dalam menegakkan dan mempertahankan kondisi ideal yang diuraikan pada tiga urusan di atas, perlu diketahui masyarakat. Himbauan agar mereka ikut aktif berperan dapat dilakukan dan dinyatakan dalam bentuk berbagai kegiatan dengan harapan warga dapat berperan dalam menuju masyarakat multiliterat.

Pihak dunia usaha dan dunia industri (DUDI) setempat dapat mendukung keberlangsungan program komunikasi PEMDA dan masyarakat dengan membayar pemasangan iklan produk mereka. Dana dari pembayaran iklan ini dapat dimanfaatkan untuk keberlangsungan penayangan informasi. Dialog interaktif dapat dilakukan dengan menyertakan media komunikasi langsung antara warga dan staf PEMDA berdasarkan informasi yang diterima warga melalui videotron. Kepedulian dan berpikir kritis mereka diharapkan terlatih. Hal penting yang perlu dilakukan adalah bagaimana membuat tata wilayah sehingga dapat menyajikan informasi tertulis yang ramah dan memadai agar pendatang tidak mengalami kesulitan di dalam berkegiatan di wilayah desa Teloyo tersebut. Efektivitas media dapat diketahui staf PEMDA dengan melakukan asesmen terhadap media komunikasi yang digunakan. Badan Pusat Statistik lokal dan Bappeda dapat menjadi pendukung utama dalam upaya memultiliterasikan warga Desa Teloyo, Kecamatan Wonosari, Kabupaten Klaten ini

\section{DAFTAR PUSTAKA}

AG. Eka Wenats Wuryanta, (2016) Pergeseran Epistemik dalam Teori Komunikasi Massa ke Komunikasi Bermedia, Universitas Paramadina, Jakarta

Awich Alhumami, (2018) Prioritas Nasional Pembangunan Manusia, Jakarta

Azis Toba, (2017) Paradigma Pembelajaran Berbasis Multiliterasi di Abad 21, Universitas Muhammadiyah Makassar

Demografi, (2018) Demografi Desa Teloyo, Kecamatan Wonosari Klaten

Dinas Pendidikan Kabupaten Klaten, (2020) Rapat Koordinasi Evaluasi Akhir Tahun 2020 dan Persiapan Tahun 2021, Klaten

Direktorat Kemitraan dan Penyelarasan Dunia Usaha dan Dunia Industri, (2018) Direktorat Jenderal Pendidikan Vokasi, Jakarta

Junaidi Alwi, (2014) Definisi dan arti Vidiotron; https://junaedialwi.com/definisivideotron/

Mendikbud, (2017) Penghargaan Literasi Prioritas, Jakarta

Pangesti Wiedarti, (2017) Ketua Satgas Gerakan Literasi Sekolah Kemendikbud Yogyakarta Dosen Sastra Indonesia, FBS, Universitas Negeri Yogyakarta, pangesti@uny.ac.id

Puspendik Kemdikbud. (2016) Kemampuan Membaca Siswa SD Kelas IV

Sri Mulyani Indrawati, (2017) Pertemuan Tahunan Dana Moneter International (IMF) dan Bank Dunia, Washington DC, US 
Sri Suharmini Wahyuningsih, (2017) Media Sosial dan Multiliterasi di Era Digital, Jurusan Ilmu Komunikasi Universitas Terbuka

Teks pidato pembukaan disampaikan kepada Wapres Jusuf Kalla, Menteri Bappenas, Menkeu, Dirjen Bangda, dan para narasumber pada Rakornas Bidang Perpustakaan 2018, di Jakarta, 26-28 Maret 2018.

U'um Qomariyah, (2017) Pengembangan Kecakapan Multiliterasi Melalui Strategi

Membangun Komunitas Literasi Terpadu Sebagai Upaya Penguatan Karakter, Universitas Negeri Semarang Pos-el: uum@mail.unnes.ac.id

Undang-Undang Republik Indonesia, (2014) Nomor 23 Tahun 2014 tentang Pemerintahan Daerah

USAID Indonesia, (2020) Pembangunan Kapasitas Sumber Daya Manusia Dan Kemitraan https://www.usaid.gov/id/indonesia/education

Y Solihin, (2017) Pembelajaran Multiliterasi, Didesain Untuk Mampu Menghubungkan 4 Keterampilan Multiliterasi. (Membaca, Menulis, Berbahasa Lisan, dan Ber-IT), Jakarta 